\title{
BMJ Open Impact of oral self-care on incident functional disability in elderly Japanese: the Ohsaki Cohort 2006 study
}

\author{
Shino Bando, ${ }^{1}$ Yasutake Tomata, ${ }^{1}$ Jun Aida, ${ }^{2}$ Kemmyo Sugiyama, ${ }^{1}$ \\ Yumi Sugawara, ${ }^{1}$ Ichiro Tsuji ${ }^{1}$
}

To cite: Bando S, Tomata $Y$, Aida J, et al. Impact of oral self-care on incident functional disability in elderly Japanese: the Ohsaki Cohort 2006 study. BMJ Open 2017;7:e017946. doi:10.1136/ bmjopen-2017-017946

- Prepublication history and additional material for this paper are available online. To view please visit the journal (http:// dx.doi.org/10.1136/bmjopen2017-017946).

Received 29 May 2017 Revised 7 August 2017 Accepted 30 August 2017

\section{CrossMark}

${ }^{1}$ Division of Epidemiology, Department of Health Informatics and Public Health, Tohoku University School of Public Health, Graduate School of Medicine, Sendai, Miyagi, Japan

${ }^{2}$ Department of International and Community Oral Health, Tohoku University Graduate School of Dentistry, Sendai, Miyagi, Japan

Correspondence to

Dr Yasutake Tomata;

y-tomata@med.tohoku.ac.jp

\section{ABSTRACT}

Objectives To assess whether oral self-care (tooth brushing, regular dental visits and use of dentures) affects incident functional disability in elderly individuals with tooth loss.

Design A 5.7-year prospective cohort study.

Setting Ohsaki City, Japan.

Participants 12370 community-dwelling individuals aged 65 years and older.

Primary outcome measures Incident functional disability (new long-term care insurance certification).

Results The 5.7-year incidence rate of disability was $18.8 \%$. In comparison with participants who had $\geq 20$ teeth, the HRs $(95 \% \mathrm{Cls})$ for incident functional disability among participants who had $10-19$ and $0-9$ teeth were 1.15 (1.01-1.30) and 1.20 (1.07-1.34), respectively ( $p$ trend<0.05). However, the corresponding values for those who brushed their teeth $\geq 2$ times per day were not significantly higher in the ' $10-19$ teeth' and '0-9 teeth' groups (HRs $(95 \% \mathrm{Cl}) 1.05(0.91-1.21)$ for participants with 10-19 teeth, and 1.09 (0.96-1.23) for participants with 0-9 teeth), although HRs for those who brushed their teeth $<2$ times per day were significantly higher (HRs $(95 \% \mathrm{Cl}) 1.32(1.12-1.55)$ for participants with 10-19 teeth, and 1.33 (1.17-1.51) for participants with 0-9 teeth). Such a negating association was not observed for other forms of oral self-care.

Conclusions Tooth brushing may partially negate the increased risk of incident functional disability associated with having fewer remaining teeth.

\section{INTRODUCTION}

As society ages, disability prevention has become an important public health issue. It has been pointed out by the WHO that oral health is an important component of healthy ageing, particularly in the disadvantaged elderly. ${ }^{1}$ Tooth loss is also known to be a risk factor for mortality in the elderly. ${ }^{2}{ }^{3}$ Periodontal disease, which is one of the main causes of tooth loss, is known to be related to coronary heart disease, ${ }^{4}$ stroke $^{4}$ and pneumonia, ${ }^{5}$ which in turn are major causes of incident disability. ${ }^{6}$ Recently, several studies have indicated that tooth loss is related to incident disability. ${ }^{78}$ Therefore,

\section{Strengths and limitations of this study}

- Our study is the first reported study to have demonstrated an impact of tooth brushing on the increased risk of incident functional disability resulting from having fewer remaining teeth.

- This is a large population-based cohort study involving 12370 individuals and it can take into account considerable confounding factors.

- Although misclassification of the number of teeth and practicing oral self-care as a result of selfreporting might have occurred, the validity of these have also been confirmed by previous studies.

there is a need to decrease the excess risk of functional disability in elderly adults with missing teeth.

It has been suggested that oral self-care has a preventative impact on mortality. ${ }^{9}$ We have reported that individuals who practiced three types of oral self-care (tooth brushing, regular dental visits and use of dentures) had a lower mortality risk than those who practiced none of the three. ${ }^{9}$ Those who practiced oral self-care also had a lower risk of dementia and cardiovascular disease. ${ }^{10} 11$ These findings suggest that there are possible pathways linking oral selfcare to incident disability. Additionally, it has been reported that the intra-oral environment affects the gut microbiota and may cause systemic inflammation, ${ }^{12}$ implying a new pathway whereby poor oral hygiene may be linked to systemic disease. To our knowledge, however, only two studies have examined whether practicing oral care affects the risk of functional disability among older people with tooth loss, and those studies focused only on denture use $\mathrm{e}^{13}$ or regular dental visits. ${ }^{14}$

The aim of the present cohort study was to assess whether three types of oral selfcare (tooth brushing, regular dental visits and use of dentures) have an impact on 
incident functional disability in individuals with tooth loss.

\section{MATERIALS AND METHODS \\ Study design, setting and participants}

This study was based on data from the Ohsaki Cohort 2006 Study, whose design has been described in detail elsewhere. ${ }^{15}$ Briefly, the source population for the baseline survey comprised all men and women aged 65 years or older living in Ohsaki City, Miyagi Prefecture, northeastern Japan, on 1 December 2006. The survey included questions about the number of remaining teeth and oral self-care status, as well as items on history of disease, education level, smoking, alcohol drinking, body weight, height, psychological distress score, time spent walking per day and food intake frequency.

The baseline survey was conducted between 1 December and 15 December 2006, and the follow-up survey between 1 April 2007 and 30 November 2012. A questionnaire was distributed by the heads of individual administrative districts to all individuals aged 65 years or older living in Ohsaki city, and then collected by mail. Among 31694 subjects (12750 men and 18944 women) eligible for this analysis, 23091 (9605 men and 13486 women) provided valid responses and formed the study cohort. Among the latter respondents, we excluded 6333 individuals who did not provide written consent for review of their longterm care insurance (LTCI) information, 2102 who had already been certified as having a disability by the LTCI before the starting date of follow-up (30 March 2007), 62 who had died or moved away before the starting date of follow-up, 188 for whom the Doctor's Opinion Paper had been unavailable and 2036 who left blank the item concerning dental health status. Thus, 12370 responses were analysed for the purpose of this study.

During the 5.7-year period covered by the study, only 158 individuals were lost to follow-up because they moved away from the study area without developing any functional disability; thus, the follow-up rate was $98.7 \%$. From 61581 person-years, incident functional disability was recorded in 2329 persons, and the number of all-cause deaths was 1446 .

\section{Measurement of dental health status}

In the baseline questionnaire, we asked respondents to classify the number of their remaining teeth into six categories: all (28 teeth), most (25-27 teeth), moderate (20-24 teeth), about half (10-19 teeth), few (1-9 teeth) and none $(0$ teeth). Then, we divided the respondents into three groups: (1) $\geq 20$ teeth, (2) 10-19 teeth and (3) 0-9 teeth.

We also asked whether they used dentures and whether they visited a dental clinic (including as reasons 'treatment' and 'other reasons such as dental check-ups and scaling') at least once a year. The respondents were asked to mark 'yes' or 'no' in reply. We also asked how many times participants brushed their teeth daily.

\section{Measurements of other variables}

K6 was used as an indicator of psychological distress. ${ }^{16} 17$ Using six questions, respondents were asked about their mental status over the last month. Total point scores ranged from 0 to 24. As the optimal cut-off point for mental illness in the validation study, we classified individuals with scores of $\geq 13$ as having psychological distress. ${ }^{18}$

The amount of energy intake (except that from alcohol drinking) and protein intake was calculated based on the data from the baseline survey and divided into sex-specific tertiles. The survey included questions about the frequency of recent average consumption of 39 daily food items. For estimation of energy and protein intake from the food-frequency questionnaire (FFQ), a food composition table was used that corresponded to the items listed in the questionnaire. ${ }^{19}$ A validation study of the FFQ had been conducted previously. ${ }^{19}$

\section{LTCI system in Japan}

In this study, we defined incident functional disability as certification for LTCI in Japan, which uses a nationally uniform standard of functional disability. LTCI is a mandatory system of social insurance to assist the daily activity of frail elderly individuals. ${ }^{20}{ }^{21}$ Everyone aged 40 years and over pays premiums, and everyone aged 65 years and over is eligible for formal caregiving services. When a person applies to the municipal government for benefits, an expert investigator visits his or her home and assesses the degree of functional disability using a questionnaire developed by the Ministry of Health, Labour and Welfare. Then, the municipal government calculates the standardised scores for physical and mental functions on the basis of the certification survey sheet and assesses whether the applicant is eligible for LTCI benefits. If a person is judged to be thus eligible, the Municipal Certification Committee decides on one of seven levels of support, ranging from support level 1 to 2 , and care level 1 to care level 5. Briefly, LTCI certification levels are defined as follows. Support level 1: 'limited in instrumental activities of daily living but independent in basic activities of daily living'; care level 2: 'requiring assistance in at least one basic ADL task'; care level 5: 'requiring care in all ADL tasks'. A community-based study has shown that levels of LTCI certification are well related to the ability to perform activities of daily living, and with Mini-Mental State Examination scores. ${ }^{22}$ LTCI certification has already been used as a measure of incident functional disability in the elderly. ${ }^{723}$

\section{Follow-up and case details}

Incident functional disability was defined as LTCI certification, which was set as our endpoint. The primary outcome was new LTCI certification (support level 1 or higher), and deaths without LTCI certification were treated as censored. We obtained a data set that included information on the date of LTCI certification, emigration or death from Ohsaki City Government based on an agreement about the secondary use of data. LTCI 
certification information was provided, including care level information. All data were transferred from the Ohsaki City Government yearly each December under the agreement related to Epidemiologic Research and Privacy Protection.

\section{Ethical issues}

The return of completed questionnaires was considered to imply consent to participate in the study involving the baseline survey data and subsequent follow-up of death and emigration. Information regarding LTCI certification status was confirmed after obtaining written consent returned from the participants at the time of the baseline survey. The Ethics Committee of Tohoku University Graduate School of Medicine reviewed and approved the study protocol.

\section{Statistical analysis}

Baseline characteristics were evaluated using the $\chi^{2}$ test for categorical variables and analysis of variance for continuous variables. We used these methods to compare variables among groups with varying numbers of teeth.
First, we examined the relationship between the number of remaining teeth and incident functional disability in the entire study population. The Cox proportional hazards model was used to calculate the HRs and 95\% CIs for incident functional disability according to the categories for different numbers of remaining teeth. Participants having $\geq 20$ teeth were used as a reference category. The multivariate models were adjusted for the following variables: age $(65-69,70-74,75-79,80-84$ and $\geq 85$ years), sex, education level (age on final graduation from school $<16,16-18, \geq 19$ years, missing), smoking (never, former, current, missing), alcohol drinking (never, former, current, missing), body mass index (kg/ $\mathrm{m}^{2} ;<18.5,18.5-24.9, \geq 25.0$, missing), time spent walking daily $(<30 \mathrm{~min}$ per day, $30 \mathrm{~min}$ per day-1 hour per day, $>1$ hour per day, missing), history of disease (stroke, hypertension, myocardial infarction, diabetes mellitus), psychological distress score $(<13, \geq 13$, missing), energy intake (sex-specific tertile, missing) and protein intake (sex-specific tertile, missing).

Second, in this analysis, we examined whether a higher risk of incident disability among participants with fewer

Table 1 Relationship between number of teeth and participant characteristic $(n=12370)$

\begin{tabular}{|c|c|c|c|}
\hline \multirow[b]{2}{*}{ Characteristic } & \multicolumn{3}{|c|}{ Number of teeth } \\
\hline & $\geq 20, n=4047$ & $10-19, n=3108$ & $0-9, n=5215$ \\
\hline Women, \% & 50.0 & 53.4 & 58.2 \\
\hline Age, mean $\pm S D$ & $71.3 \pm 4.8$ & $72.8 \pm 5.2$ & $75.6 \pm 6.2$ \\
\hline \multicolumn{4}{|l|}{ Body mass index, $\mathrm{kg} / \mathrm{m}^{2}, \%$} \\
\hline$<18.5$ & 3.2 & 4.9 & 6.2 \\
\hline $18.5-24.9$ & 63.8 & 64.0 & 65.3 \\
\hline$\geq 25.0$ & 32.9 & 31.1 & 28.5 \\
\hline Current smoking, $\%$ & 11.0 & 14.5 & 14.6 \\
\hline Current alcohol drinking, $\%$ & 46.1 & 41.3 & 31.7 \\
\hline Education $<16$ years, \% & 22.9 & 27.2 & 33.7 \\
\hline Daily walking time $\geq 1$ hour, $\%$ & 29.3 & 29.1 & 26.0 \\
\hline \multicolumn{4}{|l|}{ Medical history, \% } \\
\hline Stroke & 2.2 & 2.9 & 3.1 \\
\hline Hypertension & 43.5 & 43.5 & 43.5 \\
\hline Myocardial infarction & 3.8 & 4.4 & 5.9 \\
\hline Diabetes mellitus & 10.5 & 11.5 & 12.6 \\
\hline Psychological distress, \%* & 3.4 & 4.2 & 5.6 \\
\hline Energy intake, $\mathrm{kcal} /$ day, mean $\pm \mathrm{SD} \dagger$ & $1463.5 \pm 406.9$ & $1451.9 \pm 401.7$ & $1413.8 \pm 393.7$ \\
\hline Protein intake, g/day, mean $\pm S D$ & $54.7 \pm 14.0$ & $53.6 \pm 14.3$ & $52.5 \pm 14.4$ \\
\hline Use of dentures, \% & 27.3 & 75.1 & 93.0 \\
\hline Tooth brushing (times/day) & $2.0 \pm 0.9$ & $1.9 \pm 1.1$ & $1.8 \pm 0.9$ \\
\hline \multicolumn{4}{|l|}{$\geq 1$ dental visits per year, $\%$} \\
\hline For treatment & 57.3 & 63.5 & 43.8 \\
\hline For other reasons & 39.5 & 34.3 & 19.7 \\
\hline
\end{tabular}

${ }^{*}$ Kessler six-item psychological distress scale score $\geq 13$.

†Excluding alcohol. 
teeth would persist irrespective of whether they practice oral self-care ('tooth brushing $\geq 2$ times per day', 'visiting a dentist $\geq 1$ times per year' and 'use of dentures' being defined as 'practicing oral self-care'). For this, participants were divided into the following five categories based on three oral self-care measures: (1) 'having $\geq 20$ teeth', (2) 'practicing oral self-care and having 10-19 teeth', (3) 'non-practicing and having 10-19 teeth', (4) 'practicing and having 0-9 teeth' and (5) 'non-practicing and having 0-9 teeth'. Cox proportional hazards models were used to calculate the HRs and $95 \%$ CIs for incident functional disability to compare the four categories of missing teeth with the $\geq 20$ teeth category.

All statistical analyses were performed with SAS V.9.4 (SAS), and all statistical tests were two sided. Differences at $\mathrm{p}<0.05$ were considered to be statistically significant.

\section{RESULTS}

\section{Baseline characteristics}

In the study population, women accounted for $54.3 \%$ and the mean (SD) age was 73.5 (5.4) years. Table 1 shows the participant characteristics. Those who had more teeth were younger, and were less likely to be women, current smokers and to have a history of stroke, myocardial infarction or diabetes mellitus. Having more teeth was also related to being better educated, spending more time walking, being a current drinker, and having higher energy and protein intake.

\section{Number of teeth and incident functional disability}

The number of remaining teeth was significantly associated with a higher risk of incident functional disability. The multiple adjusted HRs (95\% CIs) for incident functional disability among participants having $10-19$ and $0-9$ teeth were 1.15 (1.01-1.30) and 1.20 (1.07-1.34), respectively, compared with participants having $\geq 20$ teeth ( $p$ trend $<0.05$ ) (see online supplementary table S1).

\section{Oral self-care and incident functional disability}

Table 2 shows the relationship between oral self-care (tooth brushing, dental visits and use of dentures) and incident functional disability in the five categories. Compared with participants who had 20 or more teeth, HRs for participants who brushed their teeth $<2$ times per day were significantly higher (multivariate HRs $(95 \%$ CI) 1.32 (1.12-1.55) for participants with 10-19 teeth, and 1.33 (1.17-1.51) for participants with $0-9$ teeth), but HRs for participants who brushed their teeth $\geq 2$ times per day were not significantly higher in the '10-19 teeth'

Table 2 Relationship between oral self-care and incident functional disability stratified according to number of teeth $(n=12370)$

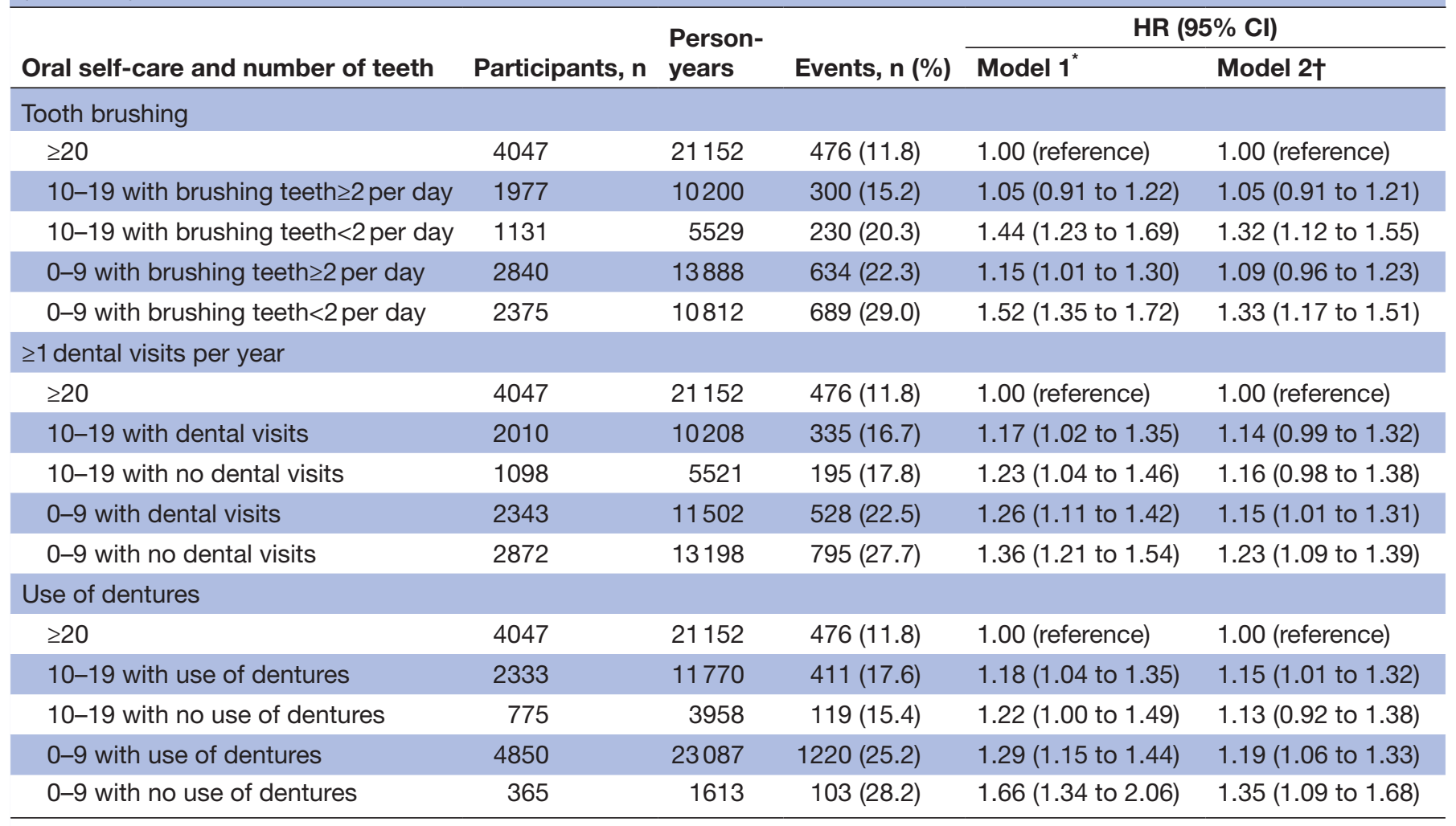

*Model 1: adjusted for age (65-69, 70-74, 75-79, 80-84 and $\geq 85$ years) and sex.

†Model 2: adjusted for model 1+education level (age on final graduation from school $<16,16-18, \geq 19$ years, missing), smoking (never, former, current, missing), alcohol drinking (never, former, current, missing), body mass index ( $\mathrm{kg} / \mathrm{m}^{2} ;<18.5,18.5-24.9$, $\geq 25.0$, missing), time spent walking daily ( $<30 \mathrm{~min} /$ day, $30 \mathrm{~min} /$ day -1 hour/day, $>1$ hour/day, missing), history of disease (stroke, hypertension, myocardial infarction, diabetes mellitus), psychological distress score $(<13, \geq 13$, missing), energy intake (sex-specific tertile, missing) and protein intake (sexspecific tertile, missing). 
Table 3 Sensitivity analysis of the relationship between oral self-care and incident functional disability according to number of teeth $(n=8323)$

\begin{tabular}{|c|c|c|c|c|c|}
\hline \multirow{2}{*}{$\begin{array}{l}\text { Oral self-care and number } \\
\text { of teeth }\end{array}$} & \multirow[b]{2}{*}{ Participants, n } & \multirow[b]{2}{*}{ Person-years } & \multirow[b]{2}{*}{ Events, n (\%) } & \multicolumn{2}{|c|}{ HR (95\% Cl) } \\
\hline & & & & Model 1* & Model 2† \\
\hline \multicolumn{6}{|l|}{$10-19$ teeth $(n=3108)$} \\
\hline Brushing teeth $\geq 2$ per day & 1977 & 10200 & $300(15.2)$ & 0.73 (0.61 to 0.87$)$ & $0.80(0.66$ to 0.96$)$ \\
\hline No dental visits & 1098 & 5521 & $195(17.8)$ & 1.00 (reference) & 1.00 (reference) \\
\hline No use of dentures & 775 & 3958 & $119(15.4)$ & 1.00 (reference) & 1.00 (reference) \\
\hline Use of dentures & 2333 & 11770 & $411(17.6)$ & 0.97 (0.79 to 1.19$)$ & $1.00(0.81$ to 1.23$)$ \\
\hline \multicolumn{6}{|l|}{$0-9$ teeth $(n=5215)$} \\
\hline Brushing teeth $<2$ per day & 2375 & 10812 & $689(29.0)$ & 1.00 (reference) & 1.00 (reference) \\
\hline Brushing teeth $\geq 2$ per day & 2840 & 13888 & $634(22.3)$ & 0.75 (0.67 to 0.84$)$ & $0.81(0.73$ to 0.91$)$ \\
\hline Use of dentures & 4850 & 23087 & $1220(25.2)$ & 0.78 (0.64 to 0.96$)$ & 0.88 (0.71 to 1.07$)$ \\
\hline
\end{tabular}

*Model 1: adjusted for age (65-69, 70-74, 75-79, 80-84 and $\geq 85$ years) and sex.

†Model 2: adjusted for model 1+education level (age on final graduation from school <16, 16-18, $\geq 19$ years, missing), smoking (never, former, current, missing), alcohol drinking (never, former, current, missing), body mass index $\left(\mathrm{kg} / \mathrm{m}^{2} ;<18.5,18.5-24.9\right.$, $\geq 25.0$, missing), time spent walking daily ( $<30 \mathrm{~min} /$ day, $30 \mathrm{~min} /$ day -1 hour/day, $>1$ hour/day, missing), history of disease (stroke, hypertension, myocardial infarction, diabetes mellitus), psychological distress score $(<13, \geq 13$, missing), energy intake (sex-specific tertile, missing) and protein intake (sexspecific tertile, missing).

and '0-9 teeth' groups (multivariate HRs (95\% CI) 1.05 (0.91-1.21) for participants with 10-19 teeth, and 1.09 (0.96-1.23) for participants with 0-9 teeth). There was no significant difference in the increased risk between these two subgroups, irrespective of whether or not participants undertook dental visits or used dentures. We analysed 'dental visits for other reasons (such as dental check-ups and scaling)' as an exposure (see online supplementary table S2). Compared with participants who had 20 or more teeth, only the HR for participants who had 10-19 teeth and visited a dentist was not significant. No such relationship was observed for 'dental visits for treatment' as an exposure.

Additionally, we compared HRs for participants who did and did not practice oral self-care in each of the '10-19 teeth' and '0-9 teeth' subgroups (table 3). Compared with participants who brushed their teeth $<2$ times per day, HRs for participants who brushed their teeth $\geq 2$ times per day were significantly lower (multivariate HRs (95\% CI) $0.80(0.66-0.96)$ for participants with 10-19 teeth ( $p$ value $<0.001)$, and $0.81(0.73-0.91)$ for participants with $0-9$ teeth $(\mathrm{p}$ value $<0.05))$. However, there was no significant difference in either of these subgroups, irrespective of whether or not participants undertook dental visits or used dentures. When we conducted reanalysis after excluding the participants with ' 0 teeth', the results did not change substantially: 0.80 (0.69-0.94) for participants with 1-9 teeth.

\section{DISCUSSION}

This cohort study investigated the association between oral self-care and incident functional disability. First, we found that tooth loss was significantly associated with an increased risk of incident functional disability, in agreement with previous studies. ${ }^{7} 8$ However, even among participants who had fewer remaining teeth, the risk for those who brushed their teeth frequently was not significantly higher. Among participants who had 10-19 teeth, we also observed a similar result for those who made dental visits for other reasons (such as dental check-ups and scaling). Our study suggested that if individuals with fewer than 20 teeth practiced good oral self-care habits such as regular tooth brushing and preventive dental visits, they might partially negate the expected increase in incident functional disability. This study had a number of strengths: (1) it was a large population-based cohort study involving 12370 individuals, (2) it had a follow-up rate of almost $100 \%$, (3) it took into account considerable confounding factors and (4) it is the first reported study to have demonstrated an impact of tooth brushing on the increased risk of incident functional disability resulting from having fewer remaining teeth.

There are several possible pathways linking oral self-care to incident functional disability. First, periodontal disease is related to systemic inflammation through oral inflammation. ${ }^{24}$ Second, a recent report has suggested that swallowing of oral bacteria affects the gut microbiota, causing 
systemic inflammation. ${ }^{12}$ Chronic inflammation is known to be a risk factor for atherosclerotic diseases including stroke $^{25}$ and dementia, ${ }^{26}$ and may cause autoimmune disease, particularly rheumatoid arthritis. ${ }^{27}$ These diseases and their symptoms are common causes of functional disability in the Japanese elderly population. ${ }^{28}$ Indeed, a previous study has suggested that tooth brushing ameliorates the risk of cardiovascular disease. ${ }^{11}$ Therefore, better oral hygiene through tooth brushing may reduce the risk of functional disability in the elderly.

This study had several limitations. First, misclassification of the number of teeth and practicing oral self-care as a result of self-reporting might have occurred. However, the validity of the self-reported number of teeth has been confirmed by previous studies ${ }^{29}$ and similarly the validity of self-reported dental visits has also been confirmed. ${ }^{30}$ Second, among the source population of 31 694, the rate of valid responses $(72.9 \%, \mathrm{n}=23091)$ for this study was not high. In addition, the valid responses would have shown a bias towards healthier people living in the community. However, this bias would not have affected the internal validity of the association between oral selfcare and incident functional disability. Third, we did not consider causes of incident functional disability. Thus, the mechanisms responsible for the reduction of incident functional disability risk resulting from oral self-care remained unidentified. Fourth, although we observed the preventive association even after adjusting for major characteristics/behaviour, not all potential confounding factors were considered. For example, although cognitive function and income might be possible confounders, we did not include them as adjustment items.

In conclusion, this study has shown that tooth brushing may partially negate the increased risk of incident functional disability resulting from having fewer remaining teeth. Further studies will need to confirm the effects of oral self-care on incident functional disability in individuals with missing teeth.

Acknowledgements We would like to thank Yoshiko Nakata, Mami Takahashi and Shu Zhang for their technical assistance.

Contributors Study concept and design: YT, IT. Acquisition of data: YT, KS, IT. Analysis and interpretation of data: SB, YT, JA, YS, IT. Drafting of the manuscript: SB, YT, IT. Critical revision of the manuscript for important intellectual content: SB, YT, JA, KS, YS, IT. All authors read and approved final manuscript.

Funding This study was supported by grants from the Foundation for Total Health Promotion (H27-General Research grants), and Health Sciences Research grants (nos. H26-Junkankitou [Seisaku]-Ippan-001 and H29-Junkankitou-Ippan-003) from the Ministry of Health, Labour and Welfare of Japan. The authors declare no potential conflicts of interest with respect to the authorship and/or publication of this article.

Competing interests None declared.

Ethics approval The Ethics Committee of Tohoku University Graduate School of Medicine.

Provenance and peer review Not commissioned; externally peer reviewed.

Data sharing statement № additional data are available.

Open Access This is an Open Access article distributed in accordance with the Creative Commons Attribution Non Commercial (CC BY-NC 4.0) license, which permits others to distribute, remix, adapt, build upon this work non-commercially, and license their derivative works on different terms, provided the original work is properly cited and the use is non-commercial. See: http://creativecommons.org/ licenses/by-nc/4.0/

(C) Article author(s) (or their employer(s) unless otherwise stated in the text of the article) 2017. All rights reserved. No commercial use is permitted unless otherwise expressly granted.

\section{REFERENCES}

1. OcA BJ, Cassels A. World report on ageing and health. World Health Organization 2015 http://www.who.int/ageing/publications/worldreport-2015/en/ (accessed 11 Oct 2016).

2. Abnet CC, Qiao YL, Dawsey SM, et al. Tooth loss is associated with increased risk of total death and death from upper gastrointestinal cancer, heart disease, and stroke in a Chinese population-based cohort. Int J Epidemiol 2005;34:467-74.

3. Holm-Pedersen P, Schultz-Larsen K, Christiansen N, et al. Tooth loss and subsequent disability and mortality in old age. J Am Geriatr Soc 2008;56:429-35.

4. Janket SJ, Baird AE, Chuang SK, et al. Meta-analysis of periodontal disease and risk of coronary heart disease and stroke. Oral Surg Oral Med Oral Pathol Oral Radiol Endod 2003;95:559-69.

5. Azarpazhooh A, Leake JL. Systematic review of the association between respiratory diseases and oral health. J Periodontol 2006;77:1465-82.

6. Wolff JL, Boult C, Boyd C, et al. Newly reported chronic conditions and onset of functional dependency. J Am Geriatr Soc 2005;53:851-5.

7. Aida J, Kondo K, Hirai $\mathrm{H}$, et al. Association between dental status and incident disability in an older Japanese population. J Am Geriatr Soc 2012;60:338-43.

8. Tsakos G, Watt RG, Rouxel PL, et al. Tooth loss associated with physical and cognitive decline in older adults. J Am Geriatr Soc 2015;63:91-9.

9. Hayasaka K, Tomata Y, Aida J, et al. Tooth loss and mortality in elderly Japanese adults: effect of oral care. J Am Geriatr Soc 2013;61:815-20.

10. Yamamoto $\mathrm{T}$, Kondo $\mathrm{K}$, Hirai H, et al. Association between selfreported dental health status and onset of dementia: a 4-year prospective cohort study of older Japanese adults from the Aichi Gerontological Evaluation Study (AGES) project. Psychosom Med 2012;74:241-8.

11. de Oliveira $C$, Watt $R$, Hamer M. Toothbrushing, inflammation, and risk of cardiovascular disease: results from Scottish Health Survey. BMJ 2010;340:c2451.

12. Arimatsu $\mathrm{K}$, Yamada $\mathrm{H}$, Miyazawa $\mathrm{H}$, et al. Oral pathobiont induces systemic inflammation and metabolic changes associated with alteration of gut microbiota. Sci Rep 2014;4:4828.

13. Shimazaki Y, Soh I, Saito T, et al. Influence of dentition status on physical disability, mental impairment, and mortality in institutionalized elderly people. J Dent Res 2001;80:340-5.

14. Komiyama T, Ohi T, Miyoshi Y, et al. Association between tooth loss, receipt of dental care, and functional disability in an elderly Japanese population: the tsurugaya project. J Am Geriatr Soc 2016;64:2495-502.

15. Kuriyama S, Nakaya N, Ohmori-Matsuda K, et al. The Ohsaki Cohort 2006 study: design of study and profile of participants at baseline. $J$ Epidemiol 2010;20:253-8.

16. Kessler RC, Barker PR, Colpe LJ, et al. Screening for serious mental illness in the general population. Arch Gen Psychiatry 2003;60:184-9.

17. Furukawa TA, Kawakami N, Saitoh M, et al. The performance of the Japanese version of the K6 and K10 in the World Mental Health Survey Japan. Int J Methods Psychiatr Res 2008;17:152-8.

18. Kuriyama S, Nakaya N, Ohmori-Matsuda K, et al. Factors associated with psychological distress in a community-dwelling Japanese population: the Ohsaki Cohort 2006 Study. J Epidemiol 2009;19:294-302.

19. Ogawa K, Tsubono $\mathrm{Y}$, Nishino $\mathrm{Y}$, et al. Validation of a food-frequency questionnaire for cohort studies in rural Japan. Public Health Nutr 2003;6:147-57.

20. Imahashi K, Kawagoe M, Eto F, et al. Clinical status and dependency of the elderly requiring long-term care in Japan. Tohoku J Exp Med 2007;212:229-38.

21. Ministry of Health Labour and Welfare. Long-Term care, health and welfare services for the elderly. http://www.mhlw.go.jp/english/policy/ care-welfare/care-welfare-elderly/ (accessed 11 Oct 2016).

22. Arai $\mathrm{Y}$, Zarit SH, Kumamoto K, et al. Are there inequities in the assessment of dementia under Japan's LTC insurance system? Int J Geriatr Psychiatry 2003;18:346-52. 
23. Tomata $\mathrm{Y}, \mathrm{Watanabe} \mathrm{T}$, Sugawara $\mathrm{Y}$, et al. Dietary patterns and incident functional disability in elderly Japanese: the Ohsaki Cohort 2006 study. J Gerontol A Biol Sci Med Sci 2014;69:843-51.

24. Loos BG. Systemic markers of inflammation in periodontitis. J Periodontol 2005;76(11 Suppl):2106-15.

25. Joshipura K, Zevallos JC, Ritchie CS. Strength of evidence relating periodontal disease and atherosclerotic disease. Compend Contin Educ Dent 2009;30:430-9.

26. Heneka MT, O'Banion MK. Inflammatory processes in Alzheimer's disease. J Neuroimmunol 2007;184:69-91.

27. Okada M, Kobayashi T, Ito S, et al. Periodontal treatment decreases levels of antibodies to porphyromonas gingivalis and citrulline in patients with rheumatoid arthritis and periodontitis. $J$ Periodontol 2013;84: e74- 84.

28. Ministry of Health Labour and Welfare. Comprehensive survey of living conditions, summary report, 2010. http://www.mhlw.go.jp/ english/database/db-hss/dl/report_gaikyo_2010.pdf (accessed 21 Dec 2016).

29. Matsui D, Yamamoto T, Nishigaki M, et al. Validity of self-reported number of teeth and oral health variables. BMC Oral Health 2016;17:17.

30. Gilbert GH, Rose JS, Shelton BJ. A prospective study of the validity of data on self-reported dental visits. Community Dent Oral Epidemiol 2002;30:352-62. 